\title{
INTRACUTANEOUS STERILE WATER INJECTION OVER SACRUM FOR THE RELIEF OF LOW BACK PAIN IN LABOUR
}

\author{
S. Valarmathy1, J. Josephine Hema²
}

${ }_{1}^{1}$ Associate Professor, Department of Obstetrics and Gynaecology, Tirunelveli Medical College, Tirunelveli, Tamilnadu, India. ${ }^{2}$ Assistant Professor, Department of Obstetrics and Gynaecology, Madurai Medical College, Madurai, Tamilnadu, India.

\begin{abstract}
\section{BACKGROUND}

Labour pain is considered to be one of the most intense and stressful experiences, especially for nulliparous woman. Pharmacological methods used to relieve labour pain like narcotics are not always warranted because of their maternal side effects, besides none of these methods have proven to be effective in reducing low back labour pain. Therefore, an effective, inexpensive and simple method with no serious side effect for reducing low back pain in labour would be very useful. Intracutaneous injection of sterile water in the skin over the sacrum has been shown to relieve the pain of labour (without causing harm to the mother and/ or foetus) or slow the labour pattern. This technique could be of particular use in hospitals that do not have access to epidural analgesia and it could also be helpful for women who want to avoid medications during labour and birth.

The aim of this study is to determine the effectiveness of intracutaneous injection of sterile water over sacrum in relieving low back pain during labour.
\end{abstract}

\section{MATERIALS AND METHODS}

200 women were divided into two groups of 100 each. Group A received 4 intracutaneous injections of 0.5 cc sterile water at the already marked 4 points in sitting position. Group B received 4 intracutaneous injections of normal saline in the same region. The pain score, rate of cervical dilatation, duration of labour, Apgar score and quality of pain relief was compared between the two groups.

\section{RESULTS}

In study and control groups, the VAS score before start of treatment was 7.62 in study group and 7.68 in control group with statistical insignificance between the two groups $(p=0.064)$. The mean pain scores at 10 mins, 45 mins and 90 mins showed a statistically significant reduction in the sterile water group when compared to the normal saline group ( $p<0.005)$. Mean duration of first stage of labour in study group was 281 minutes and in control group it was 308.5 minutes. P value was 0.003 . The difference was statistically significant. Mean duration of second stage of labour was 23.89 minutes in study group and 25.47 minutes in control group. P value was 0.0528 . It was statistically not significant. There was no prolongation of second stage of labour in the study group. Mean rate of cervical dilatation in study group was $1.8 \mathrm{~cm} / \mathrm{hr}$ and it was $1.5 \mathrm{~cm} / \mathrm{hr}$ in control group. There was a statistical significance between the two groups. There was no statistical significance between both study and control groups in regard to the duration of third stage of labour. There was no significant difference in the Apgar scores of the two groups, both at 1 minute and 5 minutes. The total duration of labour in study group was reduced (mean duration= 309.8 mins) when compared to that of the control group (mean duration= $339.3 \mathrm{mins}$ ). Among the patients in the study group, $93 \%$ had pain relief. Out of them $30 \%$ reported excellent pain relief and 34\% reported moderate pain relief, $29 \%$ had mild pain relief and $7 \%$ reporte d no pain relief. Among the patients in the control group $13 \%$ of patients reported moderate pain relief, mild pain relief was present in $53 \%$ of cases and $34 \%$ reported no pain relief.

\section{CONCLUSION}

Sterile water injections induce a statistically significant, dramatic analgesic effect on the low back pain experienced by women during labour. It augments cervical dilatation and shortens the first stage of labour. Duration of second stage of labour is not affected. There is absolutely no untoward effect on mother and foetus.

\section{KEY WORDS}

Labour - Low Back Pain - Intracutaneous Injection Over Sacrum - Sterile Water - Normal Saline.

HOW TO CITE THIS ARTICLE: Valarmathy S, Hema JJ. Intracutaneous sterile water injection over sacrum for the relief of low back pain in labour. J. Evolution Med. Dent. Sci. 2018;7(28):3151-3154, DOI: 10.14260/jemds/2018/709

'Financial or Other Competing Interest': None.

Submission 11-09-2017, Peer Review 07-06-2018,

Acceptance 14-06-2018, Published 09-07-2018.

Corresponding Author:

Dr. J. Josephine Hema,

DF4, Vanaj, Agrini Apartments,

Andalpuram, Madurai-3,

Tamilnadu, India.

E-mail: josehemaa31@gmail.com

DOI: $10.14260 /$ jemds $/ 2018 / 709$

\section{BACKGROUND}

Labour pain is considered to be one of the most intense and stressful experiences, especially for nulliparous woman.(1) Pharmacological methods used to relieve labour pain like narcotics are not always warranted, because of their maternal side effects such as drowsiness and loss of control and potential neonatal respiratory depression.(2) While epidural analgesia has become the gold standard for diminishing pain of labour and birth, it is associated with an increase in pyrexia during labour and possibility of long-term backache and neurological symptoms, also can cause sufficient motor block to adversely affect the mobility of the 
labouring women and most lose the reflex desire to push.(3) It also had an impact on breast feeding leading to lactational failure. Epidural analgesia, nitrous oxide and pudendal block which are widely used are not always available in all centres and besides none of these methods have proven to be effective in reducing low back labour pain. Therefore an effective, inexpensive and simple method with no serious side effect for reducing low back pain in labour would be very useful.(2) Intracutaneous injection of sterile water in the skin over the sacrum have been shown to relieve the pain of labour without concerns that the method might harm the mother and/ or foetus or slow the labour pattern.(4) This technique could be of particular use in hospitals that do not have access to epidural analgesia and it could also be helpful for women who want to avoid medications during labour and birth.(3)

\section{MATERIALS AND METHODS}

It is a prospective randomised control study conducted on 200 patients who were admitted in clean labour theatre at Govt. Rajaji Hospital, Madurai from Jan 2017 - June 2017. The selected 200 patients were randomised into two groups using a computer generated randomisation to receive either sterile water injection or normal saline injection. The sample size of 100 cases in each group was taken for convenience for our study.

\section{Inclusion Criteria}

1. Pregnant women with gestational age 37 - 41 weeks.

2. Patient not receiving any analgesics prior to onset of labour.

3. Patient at the onset of active phase of labour with a cervical dilatation of $2-3 \mathrm{cms}$ complaining of low back pain.

\section{Exclusion Criteria}

1. Patient not willing for the procedure.

2. Patient with contraindication for spontaneous vaginal delivery.

3. Medical disorders associated with pregnancy.

4. Infection in the area of injection.

5. Any observable spine lesions.

Informed consent was obtained. Detailed history was taken. A thorough general and obstetric examination was done. Vital parameters were recorded. Basic investigations which included urine examination for albumin, sugar, blood haemoglobin estimation, blood grouping and $\mathrm{Rh}$ typing were done. Ultrasound abdomen was performed to rule out any foetal abnormality to detect placental site, gestational age and amniotic fluid volume. Pelvic assessment to rule out CPD was performed. The women were randomised into 2 groups-

Group A- Sterile Water Injection Group.

Group B- Normal Saline Injection Group.

\section{Procedure}

1. Patient position- sitting position.

2. Anatomical points located as follows:

Point 1- The posterior superior iliac spines (dimple of venus), palpated by feeling the bony prominences just lateral to the sacrum and below the iliac crest.

Point 2-3 cms below and $1 \mathrm{~cm}$ medial to point 1 .
Point 1 and 2 on both sides form an area being referred as Michaelis' rhomboid.

3. Group A received 4 intracutaneous injections of $0.5 \mathrm{cc}$ sterile water at the already marked 4 points in sitting position. These injections were administered with $1 \mathrm{~mL}$ insulin syringe with fine 30 -gauge needle, during the peak of uterine contraction to mask any administration pain.

4. Group B received 4 intracutaneous injections of normal saline in the same region.

5. All the patients had a brief stinging pain in the sterile water group, but subsided within few seconds. Assessment of pain relief was performed using a Visual Analogue Scale (VAS), before injection, at 10 minutes, 45 minutes and 90 minutes of post administration. The acceptability of the technique by the patient was assessed in the first post-partum day by a questionnaire, stating whether the patient will accept this technique in her future labour or not.

\section{Statistical Analysis}

The information collected regarding all the selected cases were recorded in a Master Chart. Data analysis was done with the help of computer by using SPSS 16 software. Using this software means, standard deviations and 'p' values were calculated through student's ' $t$ ' test and chi-square test (For Consolidated Data) was used to test the significance. P value $<0.05$ was taken as significant.

\section{RESULTS}

The mean age of study group was 23.8 years. The mean age of control group was 24 - 39 years. There was no statistical significance in age of both groups $(\mathrm{p}=0.177) \cdot(5,6)$

In study group, $70 \%$ of the cases were booked. In control group, $66 \%$ of the cases were booked. The p-value of 0.086 was insignificant.

In study group, $68 \%$ of cases were from rural areas and $32 \%$ of cases were from urban areas. In control group, $64 \%$ of cases were from rural areas and $36 \%$ of cases from urban areas. The $\mathrm{p}$-value of 0.551 was insignificant.

In both study and control group $50 \%$ cases were primigravidae, $50 \%$ cases were multigravidae. $(7,8)$

In study group, $88 \%$ cases had intact membranes. In control group, $85 \%$ cases had intact membranes. The p-value 1.007 was insignificant. $(2,5)$

In study and control groups, the VAS score before start of treatment was 7.62 in study group and 7.68 in control group with statistical insignificance between the two groups $(\mathrm{p}=0.064) .(6,8)$ The mean pain score at 10 mins in study group was 4.34 and in control group was $5.74 . \mathrm{P}=0.043$, which was significant. The mean pain score at 45 mins in study group was 4.4 and in control group was 7.4. $\mathrm{P}=0.001$, which was significant. The mean pain score at 90 mins in study group was 4.06 and in control group was 7.6. $\mathrm{P}=0.004$, which was significant. The mean pain scores at 10 mins, 45 mins and 90 mins showed a statistically significant reduction in the sterile water group when compared to the normal saline group $(\mathrm{p}<0.005)$. 


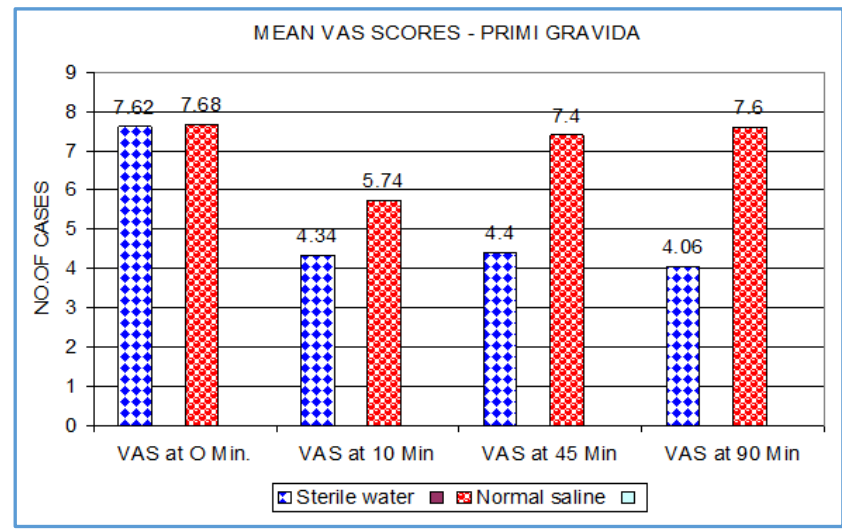

Mean duration of first stage of labour in study group was 281 minutes and in control group it was 308.5 minutes. P value was 0.003 , the difference was statistically significant.

Mean duration of second stage of labour was 23.89 minutes in study group and 25.47 minutes in control group. $\mathrm{P}$ value $=0.0528$. It was statistically not significant. There was no prolongation of second stage of labour in the study group.

Mean rate of cervical dilatation in study group was 1.8 $\mathrm{cm} / \mathrm{hr}$ and it was $1.5 \mathrm{~cm} / \mathrm{hr}$ in control group. $\mathrm{P}=0.001$, which was statistically significant. The mean rate of cervical dilatation was higher in the study group.

Mean duration of the third stage of labour was 5.35 in study group and 5.43 in control group. $\mathrm{P}=0.569$, which was statistically not significant. There was no prolongation of third stage of labour in the study group.

The mean Apgar score at $1 \mathrm{~min}$ in the study group was 7.9 and in control group was 7.8. The mean Apgar score at 5 mins in the study group was 8.5 and in control group was 8.4. There was no significant difference in the Apgar scores of the two groups, both at 1 minute and 5 minutes.

The total duration of labour in study group was reduced (mean duration $=309.8$ mins) when compared to that of the control group (mean duration= $339.3 \mathrm{mins}$ ).

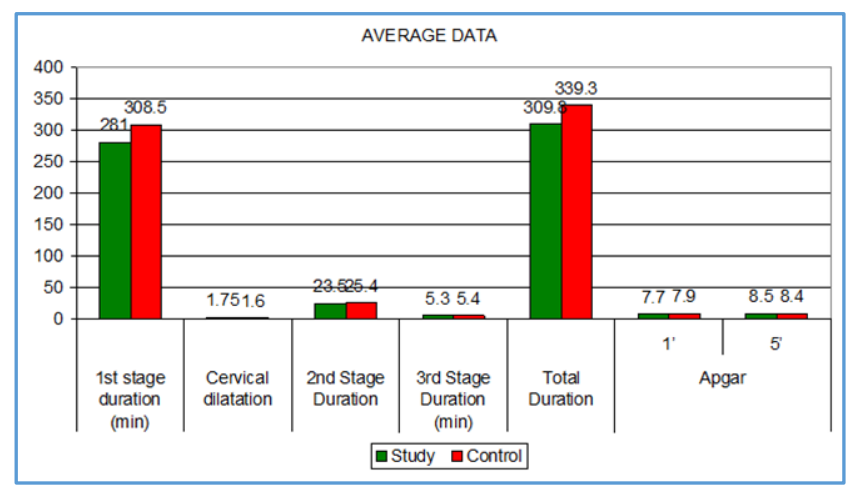

Among the patients in the study group, 93\% had pain relief. Out of them $30 \%$ reported excellent pain relief and $34 \%$ reported moderate pain relief, $29 \%$ had mild pain relief and $7 \%$ reported no pain relief. Among the patients in the control group $13 \%$ of patients reported moderate pain relief, mild pain relief was present in $53 \%$ of cases and $34 \%$ reported no pain relief. $85 \%$ of the patients in the study group said that they will accept this technique in their future labour since they had significant pain relief without any side effects.

\begin{tabular}{|c|c|c|c|c|}
\hline \multirow{2}{*}{$\begin{array}{c}\text { Quality of } \\
\text { Pain Relief }\end{array}$} & \multicolumn{2}{|c|}{$\begin{array}{c}\text { Group A } \\
\text { (Sterile Water) }\end{array}$} & \multicolumn{2}{c|}{$\begin{array}{c}\text { Group B } \\
\text { (Normal Saline) }\end{array}$} \\
\cline { 2 - 5 } & No. & \% & No. & \% \\
\hline Excellent & 30 & 30 & 0 & 0 \\
\hline Moderate & 34 & 34 & 13 & 13 \\
\hline Mild & 29 & 29 & 53 & 53 \\
\hline Nil & 7 & 7 & 34 & 34 \\
\hline Total & $\mathbf{1 0 0}$ & & $\mathbf{1 0 0}$ & \\
\hline \multicolumn{6}{|c|}{ Quality of Pain Relief } \\
\hline
\end{tabular}

\begin{tabular}{|c|c|c|}
\hline Satisfaction of Women & No. of Cases & Percentage \\
\hline Very Satisfied & 65 & 65 \\
\hline Satisfied & 25 & 25 \\
\hline Dissatisfied & 3 & 3 \\
\hline Very Dissatisfied & 7 & 7 \\
\hline Total & $\mathbf{1 0 0}$ & $\mathbf{1 0 0}$ \\
\hline Satisfaction of Women with Pain Relief provided by Sterile \\
Water \\
\hline
\end{tabular}

\section{DISCUSSION}

Sterile water injections for back pain in labour have been shown to be an effective method for relieving low back pain in labour. $(9,10)$ Analgesic mechanism of action was provided by gate control or counter irritation theory. Interruption of pain pathway by injecting hypo-osmolar solutions like sterile water produces analgesia, which is not seen with normal saline since it is iso-osmolar with blood. In our study we administered all injections intracutaneously, which produced sharp intense pain sensation that lasted for 30 seconds or more in sterile water group. The same injections can be administered subcutaneously without compromising analgesic effect. Mean pain score was lower in both intracutaneous and subcutaneous group, but the pain of administration is less with subcutaneous group.(11) An intense stimulation such as that obtained from intracutaneous sterile water injections, provided both osmotic stimulation from the salt-free water and distension of the firm cutaneous layers, was more effective than subcutaneous injections which merely induced osmotic stimulation. The pain reduction in the active stage of labour is associated with increased parasympathetic tone which improves labour, resulting in descent of the foetus and for correcting malrotation improving the likelihood of vaginal delivery.(12) Pain relief in first stage of labour had an impact on decrease in cervical tension, thereby favouring dilatation of cervix.(13) Patients on sterile water injection experience less pain during second stage without affecting the desire to push. The sterile water injection have an effect on the relaxation of pelvis and cervical tension.(14) Except for the initial deep stinging sensation lasting for 30 seconds, there were no complications in the mother. They experience pain relief for a minimum of 90 minutes to up to 2 hrs. post administration. In our study, $85 \%$ of patients in the study group said that they will accept this technique in their future labour.(12)

\section{CONCLUSION}

Sterile water injection induces a statistically significant, dramatic analgesic effect on the low back pain experienced by women during labour. It augments cervical dilatation and shortens the first stage of labour. Duration of second stage of labour is not affected. There is absolutely no untoward effect on mother and foetus. Sterile water injections represent an 


\section{Jemds.com}

important, safe, cost effective, drug free option that should be made available to all women experiencing unrelenting back pain during child birth.

\section{REFERENCES}

[1] Sheiner E, Sheiner EK, Shoham-Vardi I. The relationship between parity and labor pain. Int J Gynaecol Obstet 1998;63(3):287-8.

[2] Bahasadri S, Ahmadi-Abhari S, Dehghani-Nik M, et al. Subcutaneous sterile water injection for labour pain: a randomised controlled trial. Aust N Z J Obstet Gynaecol 2006;46(2):102-6.

[3] Reynolds JL. Intracutaneous sterile water for back pain in labour. Can Fam Physician 1994;40:1785-92.

[4] Martensson L, Wallin G. Use of acupuncture and sterile water injection for labour pain: a survey in Sweden. Birth 2006;33(4):289-96.

[5] Ader L, Hansson B, Wallin G. Parturition pain treated by intracutaneous injection of sterile water. Pain 1990;41(2):133-8.

[6] Kushtagi P, Bhanu BT. Effectiveness of subcutaneous injection of sterile water to the lower back for pain relief in labour. Acta Obstet Gynaecol Scand 2009;88(2):231-3.

\section{Original Research Article}

[7] Labrecque $M$, Nouwen $A$ Bergeron $M$, et al. A randomized controlled trial of non-pharmacologic approaches for relief of lower back pain during labor. J Fam Pract 1999;48(4):259-63.

[8] Wiruchpongsanon P. Relief of low back labor pain by using intracutaneous injections of sterile water: a randomised clinical trial. J Med Assoc Thai 2006;89(5):571-6.

[9] Peart K, James W, Deocampo J. Use of sterile water injections to relieve back pain in labour. Birth issues 2006;15(1):18-22.

[10] Peart K. Managing labour pain safely. Aust J Adv Nurs 2006;25(3):43-8.

[11] Martensson L, Wallin G. Labour pain treated with cutaneous injections of sterile water: a randomized controlled trial. $\mathrm{Br} \quad \mathrm{J}$ Obstet Gynaecol 1999;106(7):633-7.

[12] Hutton EK, Kasperink M, Rutten M, et al. Sterile water injection for labour pain: a systematic review and meta-analysis of randomised controlled trials. BJOG 2009;116(9):1158-66.

[13] Trolle B, Moller M, Kronborg H, et al. The effect of sterile water blocks on low back labor pain. Am J Obstet Gynecol 1991;164(5 Pt 1):1277-81. 